\title{
Adherence to a Diet and Exercise Weight Loss Intervention amongst Women at Increased Risk of Breast Cancer
}

\author{
Harvie M. ${ }^{*}{ }^{1}$, Cohen H. ${ }^{1}$, Mason C. ${ }^{1}$, Mercer T. ${ }^{2}$, Malik R. ${ }^{3}$, Adams J. ${ }^{3}$, Evans D.G.R. ${ }^{1}$, \\ Hopwood P. ${ }^{4}$, Cuzick J. and Howell A. ${ }^{1}$ \\ ${ }^{I}$ Genesis Prevention Centre, University Hospital of South Manchester NHS Foundation Trust, Manchester, UK \\ ${ }^{2}$ School of Health Sciences, Queen Margaret University, Edinburgh, UK \\ ${ }^{3}$ Clinical Radiology, Imaging Science \& Cancer Studies, University of Manchester. UK \\ ${ }^{4}$ Psycho-Oncology Service, The Christie NHS Foundation Trust. Manchester, UK \\ ${ }^{5}$ Cancer Research UK Departments of Epidemiology, Mathematics and Statistics, Wolfson Institute of Preventive \\ Medicine London
}

\begin{abstract}
Maintained weight loss of five percent or more may reduce risk of breast cancer. We conducted a feasibility pilot study to assess adherence to an intensive 12 month diet and exercise weight control intervention aimed to achieve and maintain a five percent or greater weight loss as compared to a usual care group receiving written advice only.

Overweight premenopausal women at increased risk of breast cancer were enrolled in a 12 month diet and exercise weight loss programme $(n=40)$ or a comparison group receiving usual care $(n=39)$. Changes in weight, general (DXA, bioelectrical impedance) and central adiposity (intra abdominal fat; MRI, waist), dietary intake, physical activity, cancer worry (Lerman score) and quality of life (SF-36) were assessed at 6 and 12 months, as well as long-term changes in weight and adiposity 12 and 42 months after the end of the intervention.

Target weight loss $(5 \%)$ was achieved by $55 \%$ of the intervention group at the end of the 12 month intervention but maintained by fewer at $24(39 \%)$ and 54 months $-(21 \%)$. Overall the intervention group achieved significant reductions in weight (mean $[95 \% \mathrm{CI}]-4.6[-6.4$ to -2.8$] \%$ ), body fat $(-4.0[-5.2$ to -2.7$]) \mathrm{kg}$, intra abdominal fat (-25.0 [-39.0 to -8.0])\% and waist circumference $(-4.0[-6.8$ to -2.0$] \mathrm{cm})$ during the 12 month intervention and reported large reductions in intake of energy (-24.3 [-33.2 to -15.1$] \%)$, fat (-32 [-44 to -20$] \%)$, and alcohol (-35 [-52 to -13$] \%)$, and increased moderate activity (27 [7 to 44$]$ minutes/day). These parameters did not change in the usual care group (all $\mathrm{P}<0.05)$. A small proportion of the usual care group lost and maintained $>5 \%$ of their weight at $6(16 \%), 12(11 \%), 24(11 \%)$ and $54(13 \%)$ months $(\mathrm{P}<0.05$ at all time points). The intervention increased physical well being (SF-36; $\mathrm{P}<0.05)$ but had no measurable effect on mental well being or cancer worry.

Weight loss is achievable within our high risk women but not more so than in previous studies in the general population. Further studies are required to better understand factors which can promote compliance in women at increased risk of breast cancer.
\end{abstract}

Keywords: Adherence, weight loss, high risk, breast cancer.

\section{INTRODUCTION}

A family history $(\mathrm{FH})$ of breast cancer is an important indicator of a woman's risk of developing the disease. These high risk women are managed in cancer family history clinics which provide risk assessment, counseling, breast screening and, where appropriate, molecular genetic testing. An increasing body of evidence suggests risk of breast

*Address correspondence to this author at the Genesis Prevention Centre, University Hospital of South Manchester NHS Foundation Trust, Manchester, M23 9LT, UK; Tel: +44 (0) 161291 4410; Fax: +44 (0) 161 291 4412; E-mail: michelle.harvie@manchester.ac.uk cancer in women and particularly those at high risk is modifiable by lifestyle factors. Specifically data support the role of excess weight [1-5], central adiposity $[6,7]$ and the possible effects of sedentary behaviour [8] on risk which appear more important than intake of specific dietary factors such as fat [9] and fruit and vegetables [10]. Amongst BRCA mutation carriers excess weight $[11,12]$, lack of exercise and diet quality [13] have been linked to increased risk and earlier onset of breast cancer. These findings are, however, based on a limited number of mainly retrospective studies. The potential risk reduction with weight loss and exercise amongst high risk women needs to be tested in a large scale prospective intervention study. 


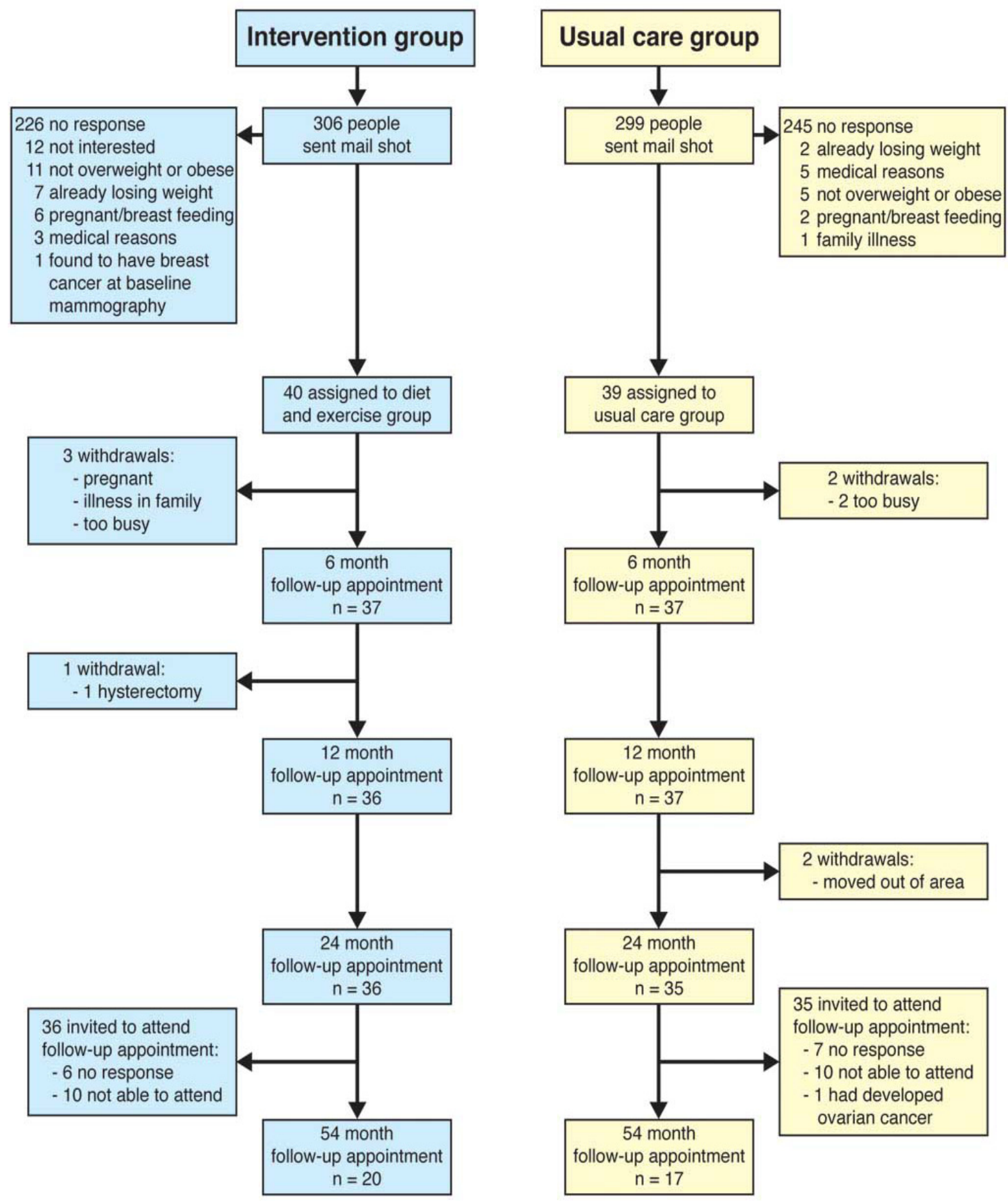

Fig. (1). Recruitment and retention to study.

Data within the general and high risk population suggest significant breast cancer risk reduction with modest weight loss $(5 \%)[14,15]$. However, even modest weight loss is known to be difficult to achieve and maintain in many patient groups [16]. Here we report a pilot study to assess uptake and adherence to a 12 month diet and exercise weight control intervention aimed to achieve and maintain a five percent or greater weight loss amongst high risk women [17]. We compared an intensive to standard written advice only to assess the relative effects of the two approaches. This will inform the feasibility and numbers required to power a future large scale weight loss breast cancer risk reduction trial. We also determined any effects of the intervention on quality of life and cancer worry to see whether these parameters were improved by the intervention and whether risk perception and level of cancer worry predicted adherence and could be potential targets to motivate adherence. 

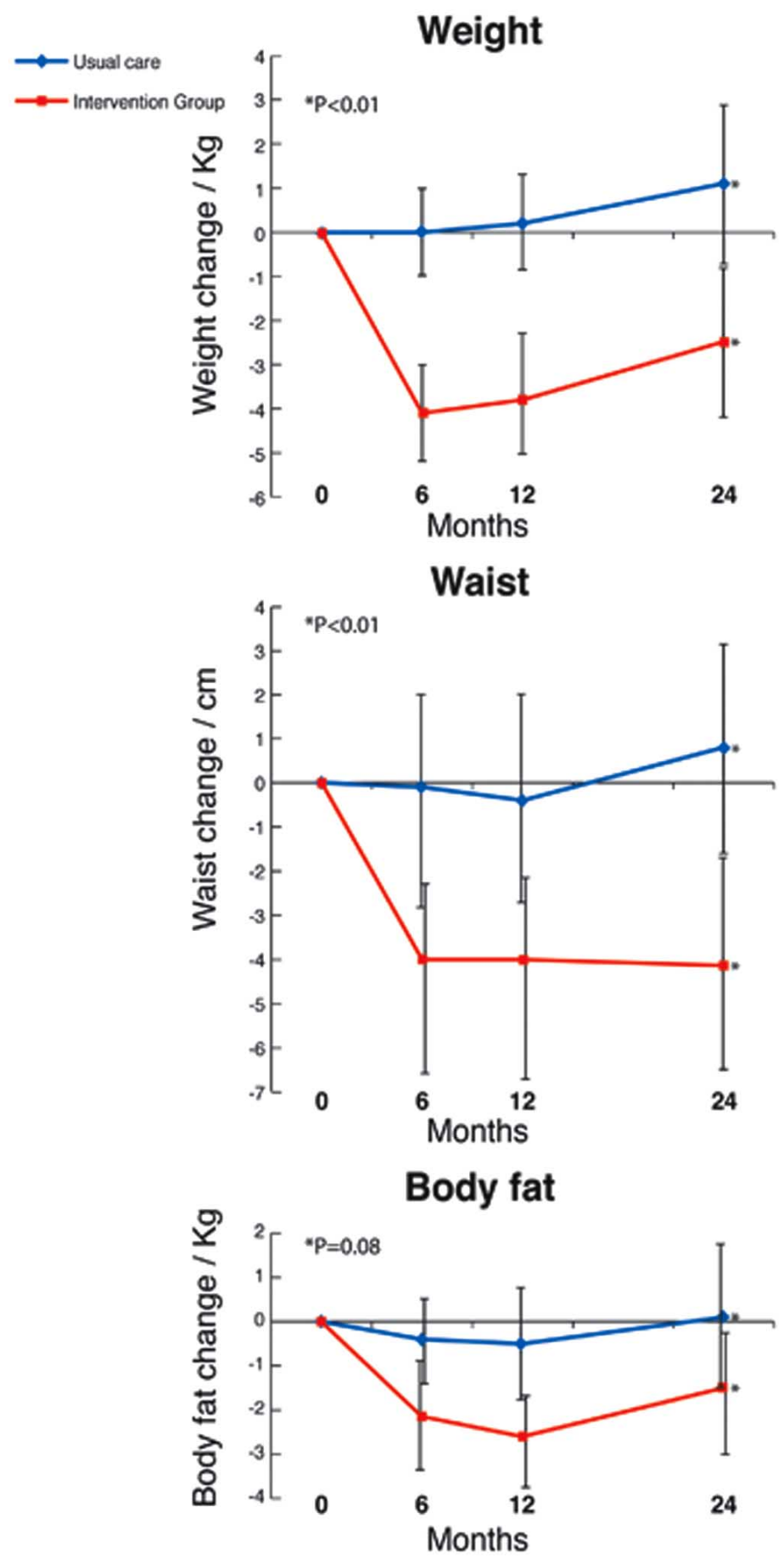

Fig. (2). Changes in weight, waist and body fat over 24 years in the intervention $(n=36)$ and usual care groups $(n=35)$.

\section{SUBJECTS AND METHODS}

\section{Subjects}

Attendees of our regional Family History Clinic (estimated lifetime breast cancer risk of $16-40 \%$ ) [18] aged $35-$ 45 received a mailed invitation to enter either a 12 month intensive diet and exercise weight loss programme or a usual care group receiving standard written advice only depending on their proximity to the hospital. Participants were required to have gained $>7 \mathrm{~kg}$ weight since the age of 20 , have $30 \%$ body fat, be sedentary, non-smokers, and premenopausal with no evidence of polycystic ovary syndrome [19] and were not taking oral contraceptives. They did not have diabetes, cardiovascular disease or previous history of cancer. Participants had previously received information of their genetic risk, and were attending annual mammographic screening. Uptake and retention within the two groups is shown in Fig. (1). All participants gave informed consent. The protocol was approved by the South Manchester Ethics Committee (Reference no 01/426). 


\section{Weight Loss Intervention}

The intervention group was advised to follow an energy restricted diet providing 500-1000 kcal below their estimated energy requirements (1.4 times $\mathrm{x}$ estimated resting energy expenditure) [20] with $20 \%$ energy from protein, $30 \%$ from fat and $50 \%$ from carbohydrate. They were also instructed to increase exercise gradually to include at least five 30 minute sessions of moderate exercise (defined as $50-60 \%$ of ageestimated maximal heart rate) each week [21], equivalent to an additional $1.4 \mathrm{kcal} / \mathrm{kg} /$ day energy expenditure. The intervention was designed to achieve a gradual weight loss of $0.5-1 \mathrm{~kg} /$ week and a weight loss of $5 \%$ or greater at 6 months and maintenance of this at 12 months. Each participant received an individualised diet and a home based exercise plan from the study dietitian $(\mathrm{MH})$ and exercise specialist (DA). To maximise compliance, they were asked to attend a weekly group exercise session for the first 12 weeks, and monthly appointments with the study dietitian throughout the 12 month intervention to assess change in weight and reinforce diet and exercise recommendations. The intervention was based on the trans theoretical model of behaviour change. A range of cog-nitive behavioural techniques such as self monitoring, obtaining peer/family support and stimulus control were encouraged to increase compliance [22].

\section{Usual Care Group}

This group were given a leaflet providing general lifestyle advice to reduce risk of cancer; to lose weight, increase exercise, increase intake of fruit and vegetables and limit intake of alcohol, fat and meat [23]. They agreed to be monitored throughout the year to assess normal changes in diet and exercise behaviour and adiposity in clinic attendees.

\section{Study Protocol}

Subjects in the intervention and usual care group were assessed at baseline, 6 and 12 months to determine any changes in weight, adiposity, dietary intake, level of physical activity, quality of life and cancer worry. Risk perception was assessed at baseline only.

\section{Weight Related Factors}

Weight, height, waist and hip circumferences were assessed using standardised methods in the morning after a 12 hour fast, wearing light clothing. Body circumferences were measured in triplicate [24]. Total body fat was measured both using a DXA whole body Hologic QDR 4500A scanner and V8.26a:3 software (Hologic Inc., Bedford, MA, USA) (coefficient of variation [CV]: fat mass $1.8 \%$, lean muscle mass $0.6 \%$ ) and using bioelectrical impedance (BI) (Tanita TBF-300A Tanita Europe BV Middlesex UK) (CV $2 \%$ ). Intra-abdominal fat (IAF) was measured using magnetic resonance imaging (MRI) with a single axial water suppressed image at the L2/L3 vertebra level, with the technician blinded to the group allocation. Overall standardised CV of IAF estimation was $7.3 \%$.

\section{Changes in Diet and Physical Activity}

Change in dietary intake was assessed using 4-day food diaries checked for completeness with the respondent. Mean energy, protein, fat and carbohydrate intake were estimated using the Compeat 4 Nutrition Analysis System (Carlson Bengston Consultants, London, UK). Change in physical activity was assessed using the validated 7-day physical activity recall questionnaire [25] expressed as $\mathrm{kcal} / \mathrm{kg} / \mathrm{day}$. We also performed a 6 minute walk test as an objective measure of fitness [26].

\section{Cancer Risk Perception, Cancer Worry and Quality of Life}

Each subject reported her personal perception of her risk of developing breast cancer through selection of the appropriate odds ratio value which ranges from 1:2 to 1:100 with additional categories of 1 for "inevitable" and 1000 for "very unlikely" [27]. Personal risk accuracy was determined by comparing self-reported odds value for personal risk with actual odds value calculated by the clinician (e.g. 1 in 4). Women were classified as under, over or accurate reporters [28].

Worry about the risk of developing cancer and the impact of worry on daily functioning was assessed using the Lerman's Cancer Worry Scale. Each item on this 6 item scale is scored from 1 to 4 giving a possible total score of 24 .

Health related quality of life was assessed using the SF36 instrument reported as physical (physical functioning, role physical, bodily pain and general health scales) and mental (vitality, social functioning, role emotional and mental health) summary scores [29].

\section{Follow Up Study}

Long-term weight loss maintenance is most likely required for cancer risk reduction. We assessed long term changes in weight and adiposity, i.e. body fat (BI) and waist circumference, in both groups. All participants were invited for a review with the study dietitian 24 and 54 months after the start of the study i.e. 12 and 42 months after the end of the 12 month intervention.

\section{Statistics}

Data are presented as the mean $(95 \%$ confidence intervals; CI), or geometric mean $(95 \% \mathrm{CI})$ for the log transformed variable intra-abdominal fat. We assessed changes in weight-related parameters, quality of life, cancer worry and diet and exercise behaviours at 6 and 12 months in the intervention group as compared to the usual care group using a last observation carried forward (LOCF) analysis of variance (ANOVA) adjusted for baseline levels of each parameter. The proportion of women achieving weight loss of $\geq 5 \%$ at 6 months and maintaining this at 12,24 , months were determined in the groups using a LOCF analysis. Since only $50 \%$ of the intervention group and $43 \%$ of the control group were reassessed at 54 month we also undertook a baseline observation carried forward analysis at this time 
point. We explored factors which may be linked to successful long-term weight loss $(>5 \%)$ by comparing preintervention levels of cancer worry (Independent $t$ test), personal risk perception scores (Mann-Whitney) and personal risk accuracy (Chi squared) between women achieving either greater than or less than 5\% weight loss at 24 months. Researchers undertaking analyses of quality of life, cancer worry and risk perception data were blinded to the study group. Data were analysed using SPSS (version 14 SPSS Ltd, Chicago, IL, USA). A 2-sided statistical significance level of $5 \%$ was used.

\section{RESULTS}

Our mail shot elicited an uptake of $13 \%$ to the intervention group. Seventy-four percent did not respond, 9\% were ineligible for medical reasons or were already losing weight. An earlier survey in our clinic suggests $50 \%$ of non responders to the mass (non-targeted) mailing had a normal BMI and thus would be ineligible [30]. Thus an estimated $24 \%$ of eligible women were recruited. Correspondingly amongst women invited to the usual care group, $81 \%$ did not respond, 5\% were not eligible; hence an estimated $24 \%$ of eligible women were recruited. There was no difference in age or risk of responders compared with non responders in either of the mailings (data not shown).

Characteristics of the intervention and usual care groups are shown in Table 1. Groups were comparable although the intervention group had a slightly higher body mass index (BMI) and lower predicted and perceived risk of breast cancer than the usual care group. These differences were not statistically significant.

The intervention group achieved significant reductions in weight (mean [95\% CI] $-4.6[-6.4$ to -2.8$] \%)$, body fat $(-4.0$ $[-5.2$ to -2.7$]) \mathrm{kg}$ intra abdominal fat $(-25.0[-39.0$ to -8.0$] \%$ and waist circumference $(-4.0[-6.8$ to -2.0$] \mathrm{cm}$ during the 12 month intervention weight mean $(95 \% \mathrm{CI})=(-4.6[-6.4$ to $2.8] \%)$, body fat $(-14.6[-19.0$ to -10.0$] \%)$, intra-abdominal fat $(-25.0[-39.0$ to -8.0$] \%$ and waist circumference $(-5.0$ [8.1 to -1.2$] \mathrm{cm}$ ) during the 12 month intervention, whilst these parameters did not change significantly in the usual care group (Table 2). The intervention group reported large reductions in dietary intake of energy $(-24.3[-33.2$ to -15.1$]$ $\%)$, fat $(-32[-44$ to -20$] \%)$, and alcohol $(-35[-52$ to -13$]$ $\%$ ). On average an additional 16 (5 to 32 ) minutes moderate intensity exercise/day by 6 months and 27 (7 to 44) minutes/ day by 12 months were undertaken. The usual care group did not report significant dietary changes but there was a shortterm increase in physical activity at 6 months which was not sustained at 12 months. At 12 months there was an objective improvement in fitness in the intervention group as compared to the usual care group assessed by the 6 minute walk test $(\mathrm{P}<0.05)$ (Table 3$)$.

The intervention group experienced a significant increase in the physical aggregate quality of life score at 12 months $(6 \%)$ which was unchanged in the usual care group $(\mathrm{P}=0.05)$. Neither the intervention nor usual care group experienced changes in mental aggregate quality of life or cancer worry scores. Neither of these scores appears to be influenced by weight loss (Table 2).

Table 1. Baseline Characteristics of the Intervention and Usual Care Groups

\begin{tabular}{|c|c|c|}
\hline & $\begin{array}{c}\text { Intervention } \\
\mathbf{N}=\mathbf{4 0}\end{array}$ & $\begin{array}{c}\text { Usual care } \\
\mathbf{N}=\mathbf{3 8}\end{array}$ \\
\hline Age (years) ${ }^{a}$ & $41.0 \pm 3.0$ & $40.2 \pm 2.8$ \\
\hline Body mass index $\left(\mathrm{Kg} / \mathrm{m}^{2}\right)^{a}$ & $30.2 \pm 7.0$ & $28.3 \pm 5.1$ \\
\hline Weight gain since aged $20(\mathrm{~kg})^{a}$ & $22.5 \pm 14.1$ & $17.2 \pm 7.3$ \\
\hline Ethnicity (\% Caucasian) & 90 & 97 \\
\hline \multicolumn{3}{|l|}{ Smoking: } \\
\hline Current & 0 & 0 \\
\hline Never & 90 & 82 \\
\hline Ever & 10 & 18 \\
\hline Predicted lifetime breast cancer risk $(\%)^{b}$ & $21 \pm 5$ & $27 \pm 7$ \\
\hline Perceived lifetime breast cancer risk $(\%)^{\mathrm{cd}}$ & $20(10-100)$ & $33(1-50)$ \\
\hline \multicolumn{3}{|l|}{ Accuracy of personal risk estimation (\%) } \\
\hline Underestimate & 25 & 26 \\
\hline Accurate & 39 & 32 \\
\hline Overestimate & 18 & 21 \\
\hline No estimates & 18 & 20 \\
\hline
\end{tabular}


Table 2. Changes in Weight, Adiposity, Cancer Worry and Quality of Life Over 12 Months in the Intervention and Usual Care Group

\begin{tabular}{|c|c|c|c|c|c|}
\hline & Baseline & Change at 6 months & P value ${ }^{3}$ & Change at 12 months & P value $^{3}$ \\
\hline \multicolumn{6}{|l|}{ Weight $(\mathrm{kg})^{1}$} \\
\hline Intervention & 80.1 (74.3 to 85.9$)$ & $-4.0(-5.1$ to -2.0$)$ & $<0.0001$ & $-3.9(-5.2$ to -2.2$)$ & $<0.0001$ \\
\hline Usual Care & $75.1(71.5$ to 80.4$)$ & $-0.4(-1.3$ to 1.6$)$ & & $0.1(-1.1$ to 1.2$)$ & \\
\hline \multicolumn{6}{|l|}{ Body fat (DXA) $(\mathrm{kg})^{1}$} \\
\hline \multicolumn{6}{|l|}{ Body fat $(\mathrm{BI})(\mathrm{kg})^{1}$} \\
\hline Intervention & 31.7 (27.6 to 35.8$)$ & $-2.4(-3.6$ to -1.2$)$ & 0.01 & $-2.7(-3.7$ to -1.6$)$ & $<0.0001$ \\
\hline Usual Care & 29.4 (25.4 to 33.6$)$ & $-0.4(-1.6$ to 0.5$)$ & & $0.5(-1.6$ to 0.7$)$ & \\
\hline \multicolumn{6}{|l|}{ Intra abdominal fat $\left(\mathrm{cm}^{2}\right)^{2}$} \\
\hline \multicolumn{6}{|l|}{ Waist circumference $(\mathrm{cm})^{1}$} \\
\hline Intervention & 99.2 (94.2 to 104.2$)$ & $-4.0(-6.7$ to -2.2$)$ & 0.02 & $-4.0(-6.8$ to -2.0$)$ & 0.03 \\
\hline Usual Care & 95.5 (91.6 to 99.4$)$ & $-0.1(-1.6$ to 1.5$)$ & & $0.4(-2.4$ to 1.6$)$ & \\
\hline \multicolumn{6}{|l|}{ Quality of life } \\
\hline \multicolumn{6}{|l|}{ Physical aggregate score ${ }^{1}$} \\
\hline Intervention & $53.2(51.4$ to 53.5$)$ & $1.3(-0.8$ to 3.4$)$ & 0.78 & $3.0(0.7$ to 5.2$)$ & 0.05 \\
\hline Usual Care & $54.1(52.1$ to 56.1$)$ & $1.1(-1.2$ to 3.5$)$ & & $-0.4(-3.4$ to 2.6$)$ & \\
\hline \multicolumn{6}{|l|}{ Quality of life } \\
\hline Mental aggregate score ${ }^{1}$ & $44.0(40.8$ to 47.2$)$ & $0.2(-4.3$ to 4.7$)$ & 0.96 & $3.2(-1.4$ to 7.8$)$ & 0.99 \\
\hline
\end{tabular}

$\mathrm{BI}=$ bioelectrical impedance, $\mathrm{DXA}=$ dual-energy $\mathrm{x}$-ray absorptiometry

${ }^{1}$ Mean $(95 \% \mathrm{CI})$ for baseline values and mean $(95 \% \mathrm{CI})$ change in LOCF value at 6 and 12 months.

${ }^{2}$ Geometric mean $(95 \% \mathrm{CI})$ for baseline values and mean $(95 \% \mathrm{CI})$ ratio of change in LOCF natural log values at 6 and 12 months.

${ }^{3} \mathrm{P}$ value for analysis of variance comparing women in intervention and usual care groups adjusted for baseline value

Baseline: Intervention 40 Usual care $39 \quad 6$ months: Intervention 38 Usual care $38 \quad 12$ months: Intervention 37 Usual care 38

We were able to reassess weight and body fat and waist in the majority of women at 24 months (36 intervention, 35 usual care), but fewer at 54 months (20 intervention, 17 usual care). Predictably both groups experienced increases in weight and body fat in the 12 months following the intervention although waist remained static in the intervention group. Weight and waist increased above baseline measurements in the usual care group. Analysis of variance (ANOVA) using last observation carried forward values at 24 months adjusted for baseline level showed significant reductions in weight and waist were sustained in the intervention compared to the usual care group $(\mathrm{P}<0.01)$ (Fig. 2). Impedance measurements showed a non-significant reduction in body fat in the intervention compared to the usual care group, which reflects the variation in body fat measurements assessed with impedance $(\mathrm{P}=0.09)$ (Fig. 2). Mean difference in body fat mass by BI and DXA in our population was $0.36 \mathrm{~kg}$. The limits of agreement (mean $\pm 2 \mathrm{SD}$ ) between the two methods were -3.8 to $+4.5 \mathrm{~kg}(-11$ to $+14 \%)$.

Target weight loss $(\geq 5 \%)$ was achieved by $55 \%$ of the intervention group at the end of the 12 month intervention period with fewer maintaining this at $24(39 \%)$ and 54 months (LOCF 32\% BOCF 21\%). A small proportion of the usual care group receiving standard written advice lost and maintained $(\geq 5 \%)$ of their weight at $6(16 \%, \mathrm{P}=0.03), 12$ $(11 \%, \mathrm{P}<0.0001), 24(11 \%, \mathrm{P}=0.01)$, and 54 months (LOCF $17 \%$ BOCF $13 \%)(\mathrm{P}=0.32)$.

We were unable to identify any psychological predictors of successful weight loss and maintenance. There was no difference in baseline cancer worry $(\mathrm{P}=0.55)$, personal risk perception score $(\mathrm{P}=0.28)$, or accuracy of risk perception 
Table 3. Changes in Dietary Intake and Physical Activity Over 12 Months in the Intervention and Usual Care Group

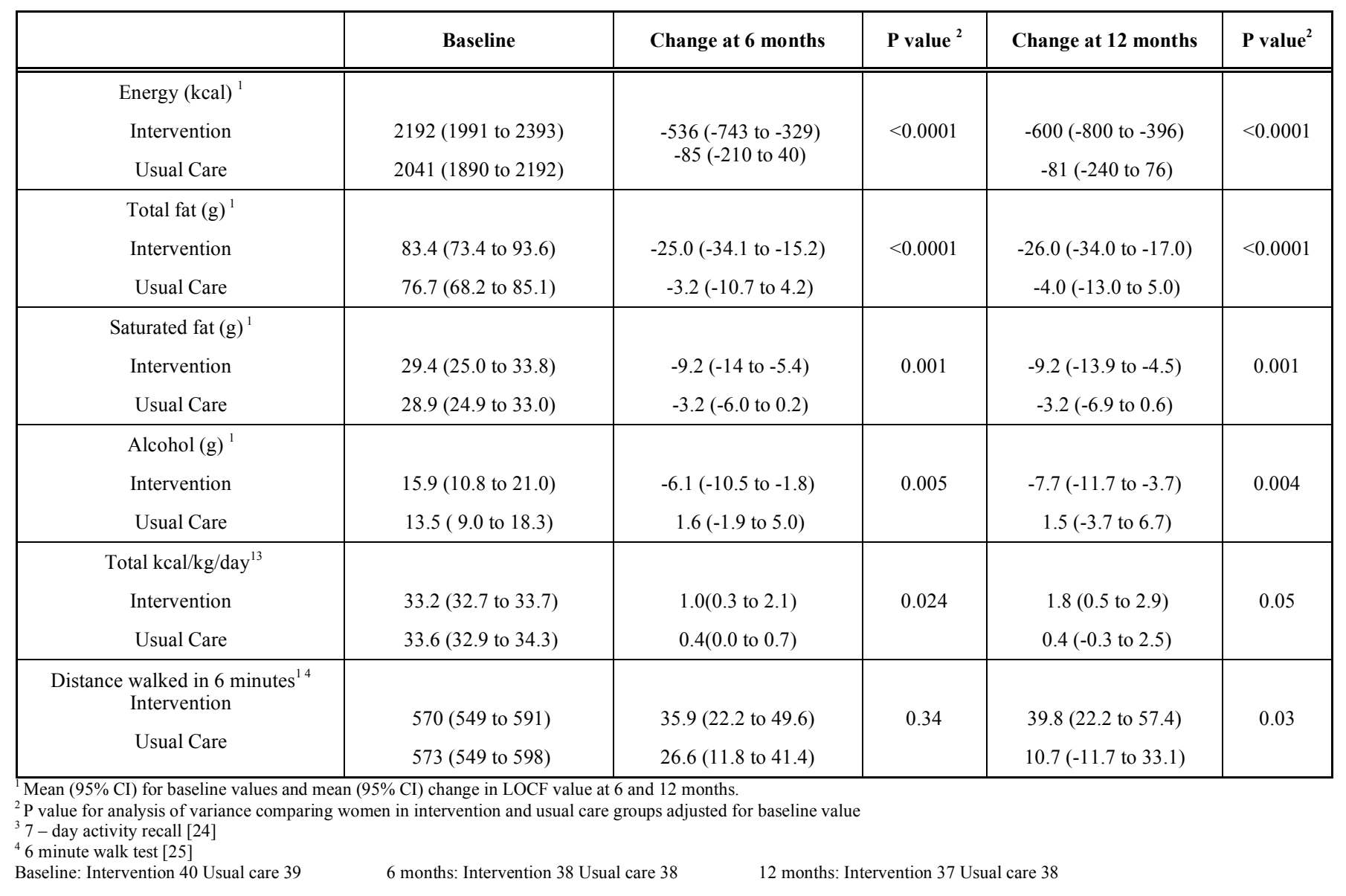

$(\mathrm{P}=0.38)$ between women who had lost and maintained $>5 \%$ weight loss at 24 months and women who did not lose weight.

\section{DISCUSSION}

\section{Main Findings}

This is the first study to report uptake and adherence to a weight loss intervention for breast cancer risk reduction amongst women at increased risk of breast cancer attending a Family History Clinic. Fifty-five percent of the intervention group achieved a clinically significant weight loss $(>5 \%)$ by the end of 12 months, with an estimated $21 \%$ maintaining this in the longer terms (54 months). In comparison a small proportion receiving usual care and standard written advice lost weight at $12(11 \%)$ and 54 months (13\%). The intervention reduced general and central adiposity and increased physical well being, but had no measurable effect on mental well being or cancer worry.

\section{Strengths of Study}

We used a comprehensive range of valid measures to assess changes in general and central adiposity (DXA, BI, MRI), dietary intake (food diaries), physical activity (7-day recall), quality of life and cancer worry during the 12 month intervention. Excellent retention to both the intervention (94\%) and usual care groups (94\%) up to 24 months, and assessment of actual rather than self reported weights at all time points [31] allowed us to accurately assess long-term weight loss maintenance and the likely impact of the intervention for cancer risk reduction. However, the predictable larger drop out by 54 months limits the validity of our findings at this time point. We assessed long-term changes in body fat using bioelectrical impedance which is known to be a valid measure of changes in body fat with weight loss in women [32].

\section{Study Limitations}

We have not examined the effects of a diet and exercise weight loss programme compared to usual care in the context of a randomised controlled trial. In common with previous research we found randomisation to a no treatment group to be unacceptable in this group of women [33]. Groups were mainly comparable at baseline, the slightly higher starting BMI and lower actual and perceived breast cancer risk in the intervention group is unlikely to have affected our findings. We studied premenopausal, non smoking women. Adherence to the intervention and their effects may differ in different groups. For example adherence to chemoprevention has shown to be lower amongst smokers [34]. We focused on premenopausal women, however, weight loss is also likely to reduce risk amongst postmeno- 
pausal women [35]. We did not include women at higher levels of risk (60-80\% lifetime risk) who are known to carry BRCA mutations. We cannot predict adherence and uptake in this higher risk group who are likely to benefit from future weight control interventions [11].

Although we used a validated self-report questionnaire to assess physical activity of the participants, such methods are subject to the potential errors associated with over-estimation of behaviour and future studies would be improved by use of objective monitoring of physical activity. Assessment of weight and anthropometrics was conducted by the study dietitian who was not blinded regarding study group assignment.

\section{COMPARISON WITH OTHER STUDIES}

The modest uptake to the intervention (13\%) reflects the usual response to mailed invitations [36]. The estimated $24 \%$ uptake amongst eligible women is considerably less than uptake to our recent red clover nutritional supplement trial (85\%) [37] but more than the $11 \%$ recruited to chemoprevention trials in our high risk women [33].

Approximately $55 \%$ of our high risk women achieved the target weight loss for risk reduction at 12 months, with $32 \%$ achieving long-term success. This compares to the $65-70 \%$ of high risk women who have been shown to comply with 5 years of chemoprevention [34].

Previous reports amongst women with a family history have focused on dietary modification and increasing exercise and have not aimed to reduce weight. Djuric et al. reported good long-term adherence to a low fat $(<20 \%)$ and increased fruit and vegetable ( 9 portions/day) intervention. After 12 months, average daily fruit and vegetable intake increased from 4 to 10 portions, whilst fat intake (as percentage of energy) decreased from $34 \%$ to $16 \%$. Adherence reduced at 24 months to 7 portions of fruit and vegetables/day and $27 \%$ of energy from fat [38]. Likewise, 6 months of telephone counseling amongst sisters of young women recently diagnosed with breast cancer increased the numbers achieving targets for physical activity (at least 90 minutes of moderate exercise/week) by $14 \%$ and for fruit and vegetable intake ( $>5$ portions of fruit and vegetables/day) by $12 \%$ [39].

The proportion of our intervention group achieving shortand long-term weight loss is comparable with those seen in other patient groups at $20-30 \%[16,40,41]$. Interestingly, a number receiving written advice only (11\%) achieved weight loss through self management as also reported in the general population [41]. Our study population of women at increased risk of breast cancer does not appear to be more motivated to adhere to a weight loss intervention than other groups of women, but this would need to be confirmed in other studies. However, the significant reductions in general $(-13 \%)$ and particularly central (-25\%) adiposity may be beneficial amongst these high risk women who have increased central fat distribution $[42,43]$.

Participants in our study had comparable cancer worry and risk perception scores to those previously reported seen in our population at increased breast cancer risk [44]. Weight loss and adherence to the diet and exercise recommendations did not appear to impact on cancer worry. Cancer worry is known to decrease with interventions which substantially decrease risk, such as bilateral prophylactic mastectomy [45], but not with previous lifestyle interventions [39], perhaps because women with genetic risk do not perceive lifestyle interventions to reduce risk.

Neither cancer worry nor risk perception appeared to influence adherence to the intervention. Moderate, but not high levels of worry can motivate attendance at mammographic screening, but little is known about the effect on other behaviours $[46,47]$. A previous analysis in our population did not link level of risk to adherence to chemoprevention agents [34]. Weight loss was linked to improvements in the physical, but not mental well being, quality of life measures, which has recently been reported amongst participants losing weight in the Diabetes Prevention Programme [48].

\section{CONCLUSION}

We have shown that weight loss is achievable within in a population of women at increased risk of breast cancer but not more than reported in other groups of women. The null associations between weight loss, cancer worry and risk perception discounts breast cancer risk reduction as a major motivator for lifestyle adherence in this group. Further psychosocial studies are required to better understand the reasons for low uptake/poor compliance in such studies and behavioural factors which promote compliance in this population. Such studies should be grounded in one of the psychological theories of behaviour change. Novel dietary approaches and modes of delivery for weight loss for cancer risk reduction are required. Future trials may test alternative approaches, such as intermittent energy restriction [49], or use of emerging technologies to communicate information, provide feedback and support to populations attending high risk clinics [50].

\section{ACKNOWLEDGEMENTS}

The authors would like to thank the Genesis Appeal for funding the study, Donna Alford for delivering the exercise intervention, Helen Sumner for coordinating sample storage and processing, and Rosemary Greenhaugh, Jenny Affen and Jean Edney for assisting in recruitment and sample collection. We dedicate this paper to Andrew Shenton (database manager) who died tragically, at a young age, on February 19th 2008.

\section{REFERENCES}

[1] Chun J, El Tamer M, Joseph KA, Ditkoff BA, Schnabel F. Predictors of breast cancer development in a high-risk population. Am J Surg 2006; 192(4): 474-7.

[2] Egan KM, Stampfer MJ, Rosner BA, et al. Risk factors for breast cancer in women with a breast cancer family history. Cancer Epidemiol Biomarkers Prev 1998; 7(5): 359-64.

[3] Carpenter CL, Ross RK, Paganini-Hill A, Bernstein L. Effect of family history, obesity and exercise on breast cancer risk among postmenopausal women. Int J Cancer 2003; 106(1): 96-102. 
[4] Hirose K, Tajima K, Hamajima N, et al. Association of family history and other risk factors with breast cancer risk among Japanese premenopausal and postmenopausal women. Cancer Causes Control 2001; 12(4): 349-58.

[5] Magnusson C, Colditz G, Rosner B, Bergstrom R, Persson I. Association of family history and other risk factors with breast cancer risk (Sweden). Cancer Causes Control 1998; 9(3): 259-67.

[6] Huang Z, Willett WC, Colditz GA, et al. Waist circumference, waist: hip ratio, and risk of breast cancer in the Nurses' Health Study. Am J Epidemiol 1999; 150(12): 1316-24.

[7] Sellers TA, Davis J, Cerhan JR, et al. Interaction of waist/hip ratio and family history on the risk of hormone receptor-defined breast cancer in a prospective study of postmenopausal women. Am J Epidemiol 2002; 155(3): 225-33.

[8] Friedenreich CM, Cust AE. Physical activity and breast cancer risk: impact of timing, type and dose of activity and population subgroup effects. Br J Sports Med 2008; 42(8): 636-47.

[9] Prentice RL, Caan B, Chlebowski RT, et al. Low-fat dietary pattern and risk of invasive breast cancer: the women's health initiative randomized controlled dietary modification trial. JAMA 2006; 295(6): 629-42.

[10] Smith-Warner SA, Spiegelman D, Yaun SS, et al. Intake of fruits and vegetables and risk of breast cancer: a pooled analysis of cohort studies. JAMA 2001; 285(6): 769-76.

[11] Kotsopoulos J, Olopado OI, Ghadirian P, et al. Changes in body weight and the risk of breast cancer in BRCA1 and BRCA2 mutation carriers. Breast Cancer Res 2005; 7(5): R833-R43.

[12] Nkondjock A, Robidoux A, Paredes Y, Narod SA, Ghadirian P. Diet, lifestyle and BRCA-related breast cancer risk among FrenchCanadians. Breast Cancer Res Treat 2006; 98(3): 285-94.

[13] Nkondjock A, Ghadirian P. Diet quality and BRCA-associated breast cancer risk. Breast Cancer Res Treat 2007; 103(3): 361-9.

[14] Eliassen AH, Colditz GA, Rosner B, Willett WC, Hankinson SE. Adult weight change and risk of postmenopausal breast cancer. JAMA 2006; 296(2): 193-201.

[15] Harvie M, Howell A, Vierkant RA, et al. Association of gain and loss of weight before and after menopause with risk of postmenopausal breast cancer in the Iowa women's health study. Cancer Epidemiol Biomarkers Prev 2005; 14(3): 656-61.

[16] Wing RR, Phelan S. Long-term weight loss maintenance. Am J Clin Nutr 2005; 82(1 Suppl): 222S-5S.

[17] Harvie M, Mercer T, Humphries G, et al. The effect of weigh loss and exercise on biomarkers of breast cancer risk - rationale and study design. Recent Res Dev Nutr 2002; 5: 91-110.

[18] Tyrer J, Duffy SW, Cuzick J. A breast cancer prediction model incorporating familial and personal risk factors. Stat Med 2004; 23(7): 1111-30.

[19] Azziz R, Carmina E, Dewailly D, et al. Positions statement: criteria for defining polycystic ovary syndrome as a predominantly hyperandrogenic syndrome: an Androgen Excess Society guideline. J Clin Endocrinol Metab 2006; 91(11): 4237-45.

[20] Schofield WN. Predicting basal metabolic rate, new standards and review of previous work. Hum Nutr Clin Nutr 1985; 39(Suppl 1): $5-41$.

[21] Jakicic JM, Clark K, Coleman E, et al. American college of sports medicine position stand. Appropriate intervention strategies for weight loss and prevention of weight regain for adults. Med Sci Sports Exerc 2001; 33(12): 2145-56.

[22] Avenell A, Sattar N, Lean M. ABC of obesity. Management: Part I-behaviour change, diet, and activity. BMJ 2006; 333(7571): 740-3.

[23] World Cancer Research Fund. Diet and health recommendations for the prevention of cancer. London, UK 2002.

[24] Seiddell J. Waist / hip and waist / thigh ratios. In Nutritioal status assessment: a manual for population studies. Fidanza F, Ed. London: Chapman and Hall 1991; pp. 335-385.

[25] Sallis JF, Haskell WL, Wood PD, et al. Physical activity assessment methodology in the five-city project. Am J Epidemiol 1985; 121(1): 91-106.

[26] White RD, Evans CH. Performing the exercise test. Prim Care 2001; 28(1): 29-53.
[27] Evans DG, Burnell LD, Hopwood P, Howell A. Perception of risk in women with a family history of breast cancer. Br J Cancer 1993; 67(3): 612-4.

[28] Hopwood P, Howell A, Lalloo F, Evans G. Do women understand the odds? Risk perceptions and recall of risk information in women with a family history of breast cancer. Commun Genet 2003; 6(4): 214-23.

[29] Hays RD, Morales LS. The RAND-36 measure of health-related quality of life. Ann Med 2001; 33(5): 350-7.

[30] Harvie M, Wilson L, Fergusson P, Evans G., Howell A. Adiposity, diet and exercise behaviours in women at increased risk of breast cancer. Abstract International Collaborative Group Familiar Breast Ovarian Cancer (ICGFBOC) Lund, Sweden September 2007.

[31] Tell GS, Jeffery RW, Kramer FM, Snell MK. Can self-reported body weight be used to evaluate long-term follow-up of a weightloss program? J Am Diet Assoc 1987; 87(9): 1198-201.

[32] Jebb SA, Siervo M, Murgatroyd PR, Evans S, Fruhbeck G, Prentice AM. Validity of the leg-to-leg bioimpedance to estimate changes in body fat during weight loss and regain in overweight women: a comparison with multi-compartment models. Int $\mathbf{J}$ Obes Lond 2007; 31(5): 756-62.

[33] Evans D, Lalloo F, Shenton A, Boggis C, Howell A. Uptake of screening and prevention in women at very high risk of breast cancer. Lancet 2001; 358(9285): 889-90.

[34] Maurice A, Howell A, Evans DG, O'Neil AC, Scobie S. Predicting compliance in a breast cancer prevention trial. Breast J 2006; 12(5): 446-50.

[35] Eliassen AH, Colditz GA, Rosner B, Willett WC, Hankinson SE. Adult weight change and risk of postmenopausal breast cancer. JAMA 2006; 296(2): 193-201.

[36] Eastwood BJ, Gregor RD, MacLean DR, Wolf HK. Effects of recruitment strategy on response rates and risk factor profile in two cardiovascular surveys. Int J Epidemiol 1996; 25(4): 763-9.

[37] Powles TJ, Howell A, Evans DG, et al. Red clover isoflavones are safe and well tolerated in women with a family history of breast cancer. Menopause Int 2008; 14(1): 6-12.

[38] Radakovich K, Heilbrun LK, Venkatranamamoorthy R, Lababidi S, Klurfeld DM, Djuric Z. Women participating in a dietary intervention trial maintain dietary changes without much effect on household members. Nutr Cancer 2006; 55(1): 44-52.

[39] Bloom JR, Stewart SL, Chang S, You M. Effects of a telephone counseling intervention on sisters of young women with breast cancer. Prev Med 2006; 43(5): 379-84.

[40] Anderson JW, Konz EC, Frederich RC, Wood CL. Long-term weight-loss maintenance: a meta-analysis of US studies. Am J Clin Nutr 2001; 74(5): 579-84.

[41] Laws R. A new evidence-based model for weight management in primary care: the Counterweight Programme. J Hum Nutr Diet 2004; 17(3): 191-208.

[42] Harvie MN, Bokhari S, Shenton A, et al. Adult weight gain and central obesity in women with and without a family history of breast cancer: a case control study. Fam Cancer 2007; 6(3): 287-94.

[43] Dettenborn L, James GD, Britton JA, Bovbjerg DH. Higher levels of central adiposity in healthy premenopausal women with family histories of premenopausal breast cancer. Am J Hum Biol 2008; 20(3): 355-8.

[44] Hopwood P, Shenton A, Lalloo F, Evans DG, Howell A. Risk perception and cancer worry: an exploratory study of the impact of genetic risk counselling in women with a family history of breast cancer. J Med Genet 2001; 38(2): 139.

[45] Metcalfe KA, Esplen MJ, Goel V, Narod SA. Psychosocial functioning in women who have undergone bilateral prophylactic mastectomy. Psychooncology 2004; 13(1): 14-25.

[46] Hay JL, McCaul KD, Magnan RE. Does worry about breast cancer predict screening behaviors? A meta-analysis of the prospective evidence. Prev Med 2006; 42(6): 401-8.

[47] McCaul KD, Branstetter AD, O'Donnell SM, Jacobson K, Quinlan KB. A descriptive study of breast cancer worry. J Behav Med 1998; 21(6): 565-79.

[48] Ackermann RT, Edelstein SL, Venkat Narayan KM, et al. Changes in Health State Utilities With Changes in Body Mass in the 
Diabetes Prevention Program. Obesity(Silver Spring) 2009; 17(12): 2176-81.

[49] Harvie M, Howell A. Energy balance adiposity and breast cancer energy restriction strategies for breast cancer prevention. Obes Rev 2006; 7(1): 33-47.
[50] Buchan I, Ainswoeth J, Hoyle D, et al. Heathcare e-labs: opening and integrating I models of health. Proc Microsoft E-Sci 2009.

Received: July 01, 2009

Revised: August 05, 2009

Accepted: August 06, 2009

(C) Harvie et al.; Licensee Bentham Open.

This is an open access article licensed under the terms of the Creative Commons Attribution Non-Commercial License (http://creativecommons.org/licenses/bync/3.0/), which permits unrestricted, non-commercial use, distribution and reproduction in any medium, provided the work is properly cited. 